\title{
Critical evaluation of platelet size as a prognostic biomarker in colorectal cancer across multiple treatment settings: a retrospective cohort study
}

\author{
D. A. Barth ${ }^{1}$ (1) J. M. RiedI ${ }^{1}$ - F. Posch ${ }^{1} \cdot$ M. A. Smolle ${ }^{1} \cdot$ A.-K. Kasparek ${ }^{1} \cdot$ T. Niedrist $^{2} \cdot$ J. Szkandera $^{1} \cdot$ H. Stöger ${ }^{1}$. \\ M. Pichler ${ }^{1,4} \cdot$ M. Stotz ${ }^{1} \cdot$ A. Gerger ${ }^{1,3}$
}

Received: 11 December 2018 / Accepted: 18 December 2018 / Published online: 22 January 2019

(c) The Author(s) 2019

\begin{abstract}
Purpose The role of mean platelet volume (MPV) as a predictor of outcomes in various cancer entities including colorectal cancer (CRC) has already been analyzed. However, data on the prognostic and predictive value of MPV in CRC over multiple lines of systemic therapy are missing.

Methods In this retrospective single-center cohort study, 690 patients with UICC stage II, III or IV CRC receiving adjuvant and/or palliative chemotherapy were included. Primary endpoints in the adjuvant, palliative and best supportive care (BSC) setting were 3-year recurrence-free survival (RFS), 6-months progression-free survival (PFS), and 6-months overall survival (OS), respectively. Kaplan-Meier estimators, log-rank tests, and uni- and multivariable Cox models were used to analyze RFS, PFS and OS. A cut-off defining patients with low MPV was chosen empirically at the 25th percentile of the MPV distribution in the respective treatment setting.

Results Three-year RFS was 76\%. Median 6-month PFS estimates in 1st, 2nd and 3rd line therapy were 59, 37 and 27\%, respectively. Median 6-month OS in BSC was 31\%. Small platelets as indicated by low MPV did not predict for shorter RFS. In the first 3 palliative treatment lines a consistent association between low MPV and decreased 6-month PFS was not observed. In the BSC setting, patients with low MPV had numerically but not significantly shorter OS. Higher MPV levels did not consistently predict for ORR or DCR across the first 3 palliative treatment lines.

Conclusion Small platelets are not predicting CRC outcomes, and thus are hardly useful for influencing clinical decision making.
\end{abstract}

Keywords Mean platelet volume $\cdot$ Biomarker $\cdot$ Colorectal cancer $\cdot$ Adjuvant chemotherapy $\cdot$ Palliative chemotherapy

$\begin{array}{ll}\text { Abbreviations } \\ \text { MPV } & \text { Mean platelet volume } \\ \text { BSC } & \text { Best supportive care } \\ \text { RFS } & \text { Recurrence-free survival } \\ \text { PFS } & \text { Progression-free survival } \\ \text { OS } & \text { Overall survival } \\ \text { ORR } & \text { Objective response rate } \\ \text { DCR } & \text { Disease control rate } \\ \text { HR } & \text { Hazard ratio }\end{array}$

Electronic supplementary material The online version of this article (https://doi.org/10.1007/s12094-019-02037-7) contains supplementary material, which is available to authorized users.

M. Stotz

michael.stotz@medunigraz.at

Extended author information available on the last page of the article
CI Confidence interval

mCRC Metastatic colorectal cancer

CTX Chemotherapy

CR Complete remission

PR Partial remission

SD Stable disease

PD Progressive disease

NE Not evaluable

NA Not applicable

\section{Introduction}

Colorectal cancer (CRC) is the third most common cancer among both men and women. However, due to changes in risk factors and the increased attendance in screening programs in developed countries, incident rates have 
been declining over the last years [1]. Nevertheless, $30 \%$ of patients with UICC stage II or III experience recurrence after resection in curative intention, $80 \%$ of which have stage III disease at diagnosis [2]. Approximately $20 \%$ of all patients present with initially metastasized UICC stage IV disease at diagnosis [3]. Therefore, it is crucial to find cost-effective and reliable prognostic biomarkers to identify patients at high risk of local or distant recurrence as well as for outcome prediction in metastasized CRC [4].

Mean platelet volume (MPV), a marker for platelet activation, is easily available in routine blood tests and has already been demonstrated to be a predictor of thrombotic events in patients with cardiovascular and cerebrovascular disease [5]. Furthermore, an association of MPV and the risk for venous thromboembolism in cancer patients has been found [6]. Evidence suggests that activated platelets might also play an important role in tumor progression by interacting with various cell types and participating in tumor proliferation related processes [7]. In addition, platelets have been shown to promote cancer angiogenesis by releasing angiogenic growth factors such as vascular endothelial growth factor (VEGF) [8].

Altered MPV has previously been analyzed as a prognostic and predictive biomarker for various tumor entities including cancers of the lung, bladder, kidney, endometrium, stomach and pancreas [9-14]. In CRC it has been shown that a higher level of MPV relates to the presence of this cancer entity, shorter overall survival (OS) and detrimental effects on progression-free survival (PFS) [15-18]. However, to the best of our knowledge MPV and its impact on the recurrence- free survival in the adjuvant setting as well as its prognostic and predictive value over multiple palliative treatment lines and best supportive care have not been investigated yet. The aim of this study is to fill this gap and evaluate the predictive and prognostic potential of pretreatment MPV in both the adjuvant and palliative setting in CRC.

\section{Methods}

\section{Study design and patients}

In this single-center observational cohort study, we retrospectively included patients with histologically-confirmed non-metastatic (UICC stage II and III) and metastatic (UICC stage IV) carcinomas of the colon or rectum who were referred to our department (Division of Oncology, Department of Internal Medicine, Medical University of Graz, Austria) between Jan, 1st, 2010 and March, 1st 2016. From these 1054 patients, we excluded 364 patients according to pre-defined criteria (Supplementary Fig. 1). Data at baseline were extracted from the electronic health record system of our hospital trust (which includes all public hospitals in the Austrian county of Styria), the internal documentation system of our department, and from paper-chart archives of our hospital. MPV results derived from routine laboratory analyses of whole blood samples drawn into EDTA-coated collection tubes (Vacuette ${ }^{\circledR}$, Greiner Bio-One, Kremsmünster, Austria). MPV was computed as the ratio of plateletcrit (PCT) to the number of platelets (PLT). In detail, PLT is determined via impedance after hydrodynamic cell focusing, while PCT results from the summation of the single impulses during PLT measurement. All measurements were performed on analyzers by Sysmex ${ }^{\circledR}$, during that 6-year span various models $\left(\mathrm{XN}-1000^{\mathrm{TM}}, \mathrm{XE}-5000^{\mathrm{TM}}\right)$ were used in the local clinical laboratory. The models do not differ in method of detection. For patients with metastatic disease, we extracted MPV values from the day of treatment initiation (for each one of the first three systemic treatment lines and at the timepoint of Best Supportive Care (BSC) initiation). For patients with non-metastatic disease, we extracted MPV values which were closest to the time of histological tumor diagnosis (within 1 week before and at a maximum of 2 weeks after histological diagnosis), but always before definitive surgery.

\section{Endpoints}

We defined the date of definitive surgery as the baseline date for patients with non-metastatic tumors. In the metastatic setting, we defined start date of the respective chemotherapy line (1st, 2nd, and 3rd) or date of BSC initiation as the baseline date, respectively. Co-Primary endpoints were Recurrence-Free Survival (RFS) in the non-metastatic setting, Progression-Free Survival (PFS) in the first three treatment lines in the metastatic setting, and Overall Survival (OS) in Best Supportive Care (BSC). Follow-up was truncated at 3 years for RFS analyses, and at 6 months for PFS and OS analyses, respectively.

\section{Ethics statement}

The study was approved by the local ethics committee (Ethikkommission der Medizinischen Universität Graz, IRB00002556) prior any patient-related activities were performed (No. 25-458 ex 12/13). Written informed consent was not obtained from individual patients, because the local ethics committee specifically granted a "waiver of consent" for this retrospective database study. All investigations have been in accordance with the principles embodied in the declaration of Helsinki.

\section{Statistical analysis}

All statistical analyses were performed using Stata (Windows version 15.0, Stata Corp., Houston, TX, USA). 
Continuous variables were summarized as medians [25th-75th percentile], whereas categorical variables were reported as absolute counts (\%). The association between response rates and MPV under study were analyzed with uni- and multivariable generalized linear models from the Bernoulli family with an identity link. Median follow-up was estimated with a reverse Kaplan-Meier (KM) estimator according to Schemper and Smith. PFS and OS was estimated with KM estimators, compared between two groups using log-rank tests, and modelled with uni- and multivariable Cox proportional hazards models. For dichotomization of MPV (necessary for all figures), an empirical cut-off at the 25th percentile of the MPV distribution in the respective treatment setting was used.

\section{Results}

\section{Analysis at baseline}

In total, 690 patients were included in the analysis of which $425,231,117,55$ and 212 patients accounted for the adjuvant, 1st-line metastatic, 2nd-line metastatic, 3rd-line metastatic, and BSC setting, respectively (Table 1). The average MPV levels were highly similar across all treatment settings (Table 1).

\section{Analysis of response patterns in the 1st to 3rd-line metastatic setting and their association with MPV}

Objective response rates (ORR) were 33\% (95\% CI 27-40) in 1st-line therapy, 24\% (16-34) in 2nd-line therapy, and 19\% (8-33) in 3rd-line therapy, respectively (Supplementary Fig. 2). Corresponding disease control rates (DCR) were 65\% (58-72), 57\% (47-67), and 42\% (27-58), respectively. Higher MPV levels did not consistently predict for ORR or DCR across treatment lines, and this prevailed in multivariable analysis adjusting for polychemotherapy (Table 2).

\section{Uni- and multivariable analysis of clinical outcomes across treatment settings}

Median PFS was not reached in 1st-line, 4.8 months in 2nd-line, and 4.1 months in 3rd-line therapy, respectively. 9-month PFS was 59\% (52-65), 37\% (28-46) and 27\% (15-41) in 1st-line, 2nd-line, and 3rd-line therapy, respectively. Median OS was 2.6 month in BSC, and 6-month OS in BSC was 31\% (23-40, Supplementary Fig. 3). Median RFS was not reached in the adjuvant setting, while 3-year RFS was 76\% (72-81, Supplementary Fig. 4).

Three-year RFS was highly similar in patients with low MPV (as defined by an empirical cut-off $<$ the 25 th percentile $(<\mathrm{Q} 1)$ of its distribution) and patients with MPV above this cut-off, respectively (log-rank $p=0.566$, Fig. 1). In univariable Cox regression, MPV levels were not associated with the rate of recurrence [Hazard Ratio (HR) per 1 $\mathrm{fL}$ increase in MPV $=0.96,95 \%$ CI $0.82-1.12, p=0.600$, Table 3]. This result prevailed after multivariable adjustment for stage III disease (Adjusted HR $=0.95,0.81-1.12$, $p=0.556$, Table 3 ).

Rates of progression in 1st- to 3rd-line therapy were higher in patients with low MPV (as defined by an empirical cut-off $<$ the 25 th percentile $(<\mathrm{Q} 1)$ of its distribution in the respective treatment setting) than in patients above this cutoff (Fig. 2a-c), although this did only reach statistical significance in the 2nd-line setting. This pattern was confirmed in uniand multivariable Cox regression, where higher MPV levels were numerically but not statistically significantly associated with a lower rate of progression in 1st- to 3rd-line metastatic settings, as well as BSC, respectively (Table 3 and Fig. 3).

\section{Discussion}

Previous studies have already analyzed MPV and its potential role as a diagnostic and prognostic biomarker in different disease and treatment settings in CRC [16-19]. However, there is a lack of information on MPV and its impact on recurrence in the adjuvant setting as well as its association with outcome in metastatic CRC over multiple systemic treatment lines. In our study, pretreatment MPV was neither a predictor for RFS in patients undergoing potentially curative resection nor significantly associated with shorter PFS in metastasized CRC, except for 2nd line treatment. Patients in BSC with MPV below the 25th percentile had numerically but not significantly shorter OS. There was no consistent influence on clinical response rates (ORR and DCR) in patients receiving 1st, 2nd and 3rd line palliative treatment, respectively.

Platelets enhance tumor progression as they carry multiple granules containing growth factors, chemokines and proteases and form a shield around tumor cells preventing them from the immune response of natural killer cells [8]. In addition, they carry prothrombotic and proinflammatory mediators and are involved in inflammatory processes and diseases [5]. MPV is a marker of platelet size and raises due to enhanced platelet activation and inflammation, the last of which plays a major role in cancer progression [5, 20]. Markers of inflammation were already shown to relate to cancer prognosis and clinical response in metastatic CRC [21], but although an increase of MPV in some cancer entities is assumed to be the result of cancer related inflammation $[13,19,22,23]$, the observation of decreased platelet size in cancer may also be explained by cancer-associated platelet activation and exhaustion [24]. Small platelets and consequently low MPV might be the result of further enhanced 


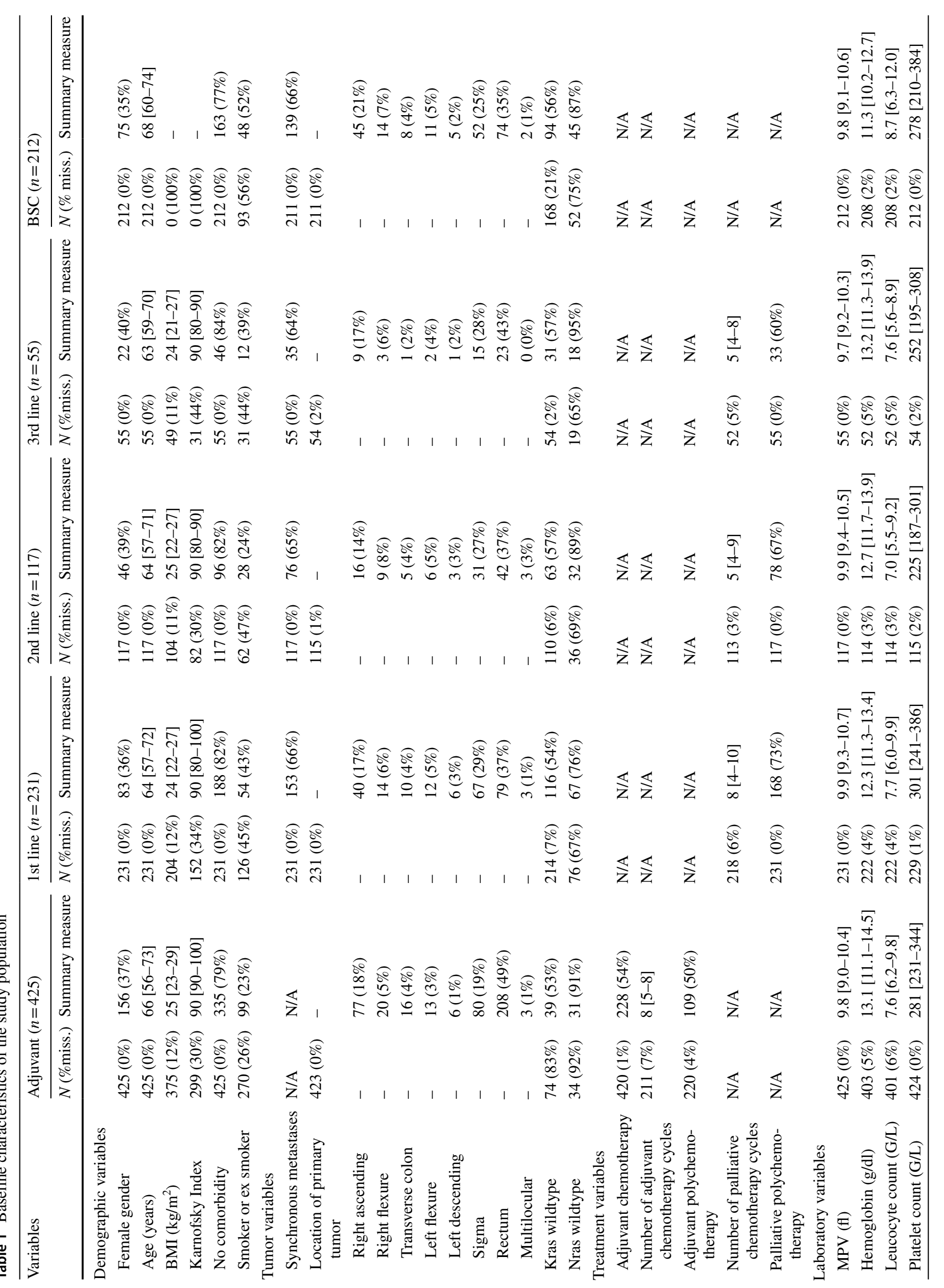


inflammation and a high consumption of large activated platelets at the tumor site, causing the release and production of smaller exhausted platelets $[5,10]$. This mechanism was shown in other diseases with systemic inflammation [5].

Interestingly, opposing MPV levels could be found in different cancer entities. On the one hand, increased MPV was present in gastric, endometrial, ovarian and liver cancer whereas on the other hand, it was decreased in non-small cell lung cancer and renal cell carcinoma $[9,12,13,15,22$, 23, 25]. In CRC the role of MPV is still not clear. Higher preoperative MPV values could be found in patients with colon cancer compared to controls, implicating that MPV might indicate the presence of colon cancer. In addition, MPV values were associated with disease progression and raised with higher stages [19]. Kilincalp et al. [26] could further show that increased MPV in CRC patients decreased after surgical removal of the tumor. Conversely, the analysis of MPV in rectal cancer alone revealed lower values at diagnosis but an increase of MPV after curative resection [18]. This might indicate a difference in the role of platelets in colon and rectal cancer but may also indicate that the cancer cells themselves influence the tumor macroenvironment (i.e. platelet function and size) [27].

In contrast to our results, prior studies found increased MPV at diagnosis to be a predictor of poor prognosis in $\mathrm{CRC}$, associated with shorter pooled OS and shorter PFS in metastatic patients receiving bevacizumab-combined chemotherapy. This was explained by a linkage between increased platelet size and increased platelet activation and consecutive greater inflammation $[16,17]$.

Nonetheless, although not statistically significant, regression coefficients across all treatment settings were in the direction that small platelets are associated with worse outcomes. This at least partly corroborates prior research in CRC and other tumors types which implicate low MPV in adverse prognosis. Moreover, our clinical data are at least hypothesis-generating for further basic research studies on platelet activation and cancer progression in CRC.

Riedl et al. [6] found a decreased MPV to be significantly associated with shorter OS when they analyzed the impact of altered MPV in cancer patients on the risk of venous thromboembolism and mortality in a prospective cohort study including 1544 cancer patients. However, the study summarizes both patients with solid as well as hematological malignancies and amongst others the subgroup analysis for 159 CRC cases showed no significant result. In addition, a recent study of our department found a highly significant association of decreased MPV and RFS as well as cancer specific death in patients with non-metastatic renal cell carcinoma [11]. Low MPV values were also shown to be associated with poor prognosis in cancers of the bladder and the lung $[9,10,28]$. 
Table 2 Uni and multivariable predictors of clinical response rates in first, second and third line

\begin{tabular}{|c|c|c|c|}
\hline Variables & $\Delta$ abs in 1 st-line $(95 \% \mathrm{CI} p)$ & $\Delta$ abs in 2nd-line (95\% CI $p$ ) & $\Delta$ abs in 3rd-line (95\% CI $p)$ \\
\hline \multicolumn{4}{|l|}{ Objective response rate $(\%)$} \\
\hline \multicolumn{4}{|l|}{ Univariable analysis } \\
\hline MPV (per 1fL increase) & $+0.8 \%(-6.8-6.9, p=0.982)$ & $+7.3 \%(-2.1-16.6), p=0.129)$ & $-7.4 \%(-15.0-0.2, p=0.058)$ \\
\hline \multicolumn{4}{|c|}{ Other predictors-Univariable analysis } \\
\hline Age (per 10 years increase) & $-7.9 \%[-14.3-(-1.5), p=0.015]$ & $-1.3 \%(-9.6-7.0, p=0.759)$ & $-13.6 \%(-21.9-(-5.2), p=0.001)$ \\
\hline Right side & $-6.8 \%(-21.6-8.0, p=0.370)$ & $13.4 \%(-8.1-35.0, p=0.221)$ & $-12.8 \%(-35.0-9.4, p=0.259)$ \\
\hline Right side in KRAS-wt & $-15.4 \%(-35.2-4.5, p=0.129)$ & $7.8 \%(-21.9-37.4, p=0.609)$ & $0.0 \%(-39.2-39.2), p=0.999)$ \\
\hline Polychemotherapy & $+22.7 \%(10.5-34.8, p<0.0001)$ & $16.9 \%(0.8-33.1, p=0.039)$ & $+19.7 \%(-0.7-40.0, p=0.058)$ \\
\hline \multicolumn{4}{|l|}{ Multivariable analysis } \\
\hline MPV (per 1fL increase) & $+1.0 \%(-5.6-7.7, p=0.764)$ & $+8.2 \%(2.4-14.1), p=0.006)$ & $\mathrm{N} / \mathrm{E}$ \\
\hline Polychemotherapy & $+19.4 \%(5.6-33.2, p=0.006)$ & $+18.4 \%(4.8-32.0, p=0.008)$ & $\mathrm{N} / \mathrm{E}$ \\
\hline \multicolumn{4}{|l|}{ Disease control rate $(\%)$} \\
\hline \multicolumn{4}{|l|}{ Univariable analysis } \\
\hline MPV (per 1fL increase) & $+4.9 \%(-1.8-11.6, p=0.154)$ & $+10.2 \%(0.6-19.7, p=0.036)$ & $-0.2 \%(-14.9-14.5, p=0.980)$ \\
\hline \multicolumn{4}{|c|}{ Other predictors-Univariable analysis } \\
\hline Age (per 10 years increase) & $-7.1 \%(-13.0-(-1.2), p=0.019)$ & $-1.2 \%(-10.6-8.1, p=0.796)$ & $-2.8 \%(-20.1-14.6, p=0.754)$ \\
\hline Right side & $+10.8 \%(-5.2-26.8, p=0.187)$ & $+21.9 \%(0.7-43.1, p=0.043)$ & $+4.8 \%(-29.2-38.8, p=0.781)$ \\
\hline Right side in KRAS-wt & $+1.8 \%(-22.1-25.7, p=0.881)$ & $+3.9 \%(-26.5-34.2, p=0.802)$ & $+15.0 \%(-33.1-63.2, p=0.542)$ \\
\hline Polychemotherapy & $+31.5 \%(15.3-47.8, p<0.0001)$ & $+31.7 \%(11.4-51.9, p=0.002)$ & $+16.9 \%(-12.6-46.4, p=0.262)$ \\
\hline \multicolumn{4}{|l|}{ Multivariable analysis } \\
\hline MPV (per 1fL increase) & $+4.5 \%(-1.8-10.9, p=0.162)$ & $+12.9 \%(4.3-21.4, p=0.003)$ & $-0.7 \%(-15.2-13.8, p=0.924)$ \\
\hline Polychemotherapy & $+31.3 \%(15.2-47.5, p<0.0001)$ & $+34.9 \%(15.8-54.0, p<0.0001)$ & $+17.0 \%(-12.6-46.6, p=0.261)$ \\
\hline
\end{tabular}

Absolute change of ORR (objective response rate) and DCR (disease control rate) per 1fL increase of MPV (mean platelet volume)

$O R R$ objective response rate, $D C R$ disease control rate, $C I$ confidence interval, $P$ p value, $M P V$ mean platelet volume, $N / E$ not evaluable

Fig. 1 Kaplan Meier curve according to MPV $\geq$ Q1 vs. $\mathrm{MPV}<\mathrm{Q} 1$ for recurrence free survival in the adjuvant setting

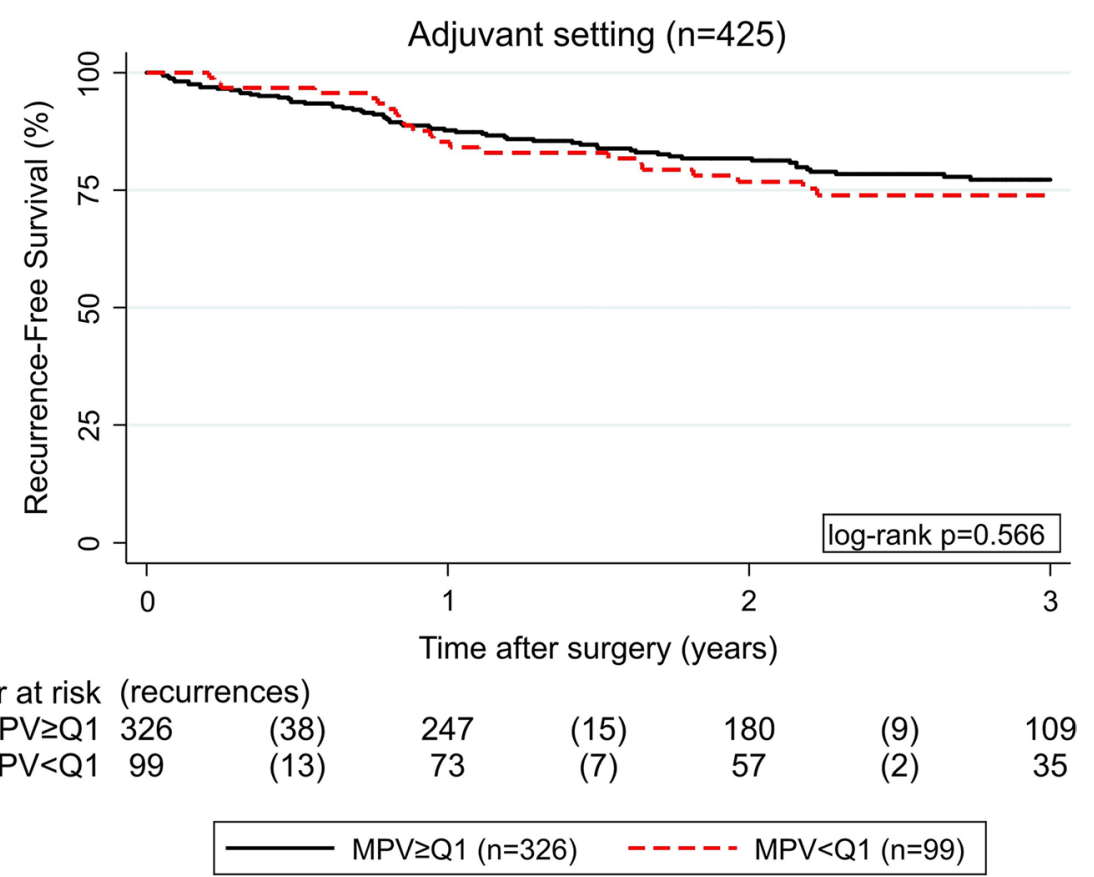


Table 3 Uni and multivariable predictors of clinical outcomes in the adjuvant setting, first, second, third line metastastic setting, and best supportive care

\begin{tabular}{|c|c|c|c|c|c|}
\hline Variables & $\begin{array}{l}\text { 3-year RFS in the } \\
\text { adjuvant setting [HR } \\
(95 \% \text { CI } p)]\end{array}$ & $\begin{array}{l}\text { 6-month PFS in 1st } \\
\text { line [HR }(95 \% \mathrm{CI} p)]\end{array}$ & $\begin{array}{l}\text { 6-months PFS in 2nd } \\
\text { line }[\mathrm{HR}(95 \% \text { CI } p)]\end{array}$ & $\begin{array}{l}\text { 6-months PFS in 3rd } \\
\text { line }[\mathrm{HR}(95 \% \mathrm{CI} p)]\end{array}$ & $\begin{array}{l}\text { 6-months OS in BSC } \\
{[\mathrm{HR}(95 \% \mathrm{CI} p)]}\end{array}$ \\
\hline \multicolumn{6}{|l|}{ Univariable analysis } \\
\hline $\begin{array}{l}\text { MPV (per } 1 \mathrm{fL} \\
\text { increase) }\end{array}$ & $\begin{array}{c}0.96(0.82-1.12 \\
p=0.600)\end{array}$ & $\begin{array}{c}0.82(0.67-1.00, \\
p=0.053)\end{array}$ & $\begin{array}{c}0.82(0.63-1.06 \\
p=0.136)\end{array}$ & $\begin{array}{c}0.87(0.62-1.22 \\
p=0.424)\end{array}$ & $\begin{array}{c}0.81(0.67-0.98 \\
p=0.031)\end{array}$ \\
\hline \multicolumn{6}{|c|}{ Other predictors-Univariable analysis } \\
\hline $\begin{array}{l}\text { Age (per } 10 \text { years } \\
\text { increase) }\end{array}$ & $\begin{array}{c}1.14(0.95-1.36 \\
p=0.164)\end{array}$ & $\begin{array}{c}1.12(0.91-1.37 \\
p=0.284)\end{array}$ & $\begin{array}{c}1.01(0.80-1.27 \\
p=0.920)\end{array}$ & $\begin{array}{c}1.34(0.88-2.04, \\
p=0.179)\end{array}$ & $\begin{array}{c}0.69(0.59-0.81, \\
p<0.0001)\end{array}$ \\
\hline Right side & N/A & $\begin{array}{c}1.23(0.78-1.95 \\
p=0.370)\end{array}$ & $\begin{array}{c}0.78(0.44-1.37 \\
p=0.383)\end{array}$ & $\begin{array}{c}1.23(0.57-2.63 \\
p=0.597)\end{array}$ & $\begin{array}{c}1.56(1.07-2.29 \\
p=0.022)\end{array}$ \\
\hline $\begin{array}{l}\text { Right side in KRAS- } \\
\text { wt }\end{array}$ & N/A & $\begin{array}{c}1.31(0.70-2.45, \\
p=0.398)\end{array}$ & $\begin{array}{c}1.34(0.67-2.68, \\
p=0.412)\end{array}$ & $\begin{array}{c}1.58(0.52-4.79, \\
p=0.423)\end{array}$ & $\begin{array}{c}1.62(0.98-2.70 \\
p=0.062)\end{array}$ \\
\hline $\begin{array}{l}\text { Stage III (vs. Stage } \\
\text { II) }\end{array}$ & $\begin{array}{c}2.14(1.29-3.53, \\
p=0.003)\end{array}$ & N/A & N/A & N/A & N/A \\
\hline $\begin{array}{l}\text { Adjuvant chemo- } \\
\text { therapy }\end{array}$ & $\begin{array}{c}0.69(0.45-1.07 \\
p=0.099)\end{array}$ & N/A & N/A & N/A & N/A \\
\hline Polychemotherapy & N/A & $\begin{array}{c}0.51(0.33-0.77 \\
p=0.002)\end{array}$ & $\begin{array}{c}0.67(0.411 .09 \\
p=0.104)\end{array}$ & $\begin{array}{c}0.94(0.47-1.86 \\
p=0.857)\end{array}$ & N/A \\
\hline $\begin{array}{l}\text { Metachronous } \\
\text { metastases }\end{array}$ & N/A & $\begin{array}{c}0.98(0.63-1.52, \\
p=0.916)\end{array}$ & $\begin{array}{c}1.13(0.70-1.83, \\
p=0.616)\end{array}$ & $\begin{array}{c}1.22(0.61-2.48 \\
p=0.573)\end{array}$ & $\begin{array}{c}0.71(0.47-1.07, \\
p=0.105)\end{array}$ \\
\hline Multivariable analysis & Adjusted for Stage III & $\begin{array}{l}\text { Adjusted for poly- } \\
\text { chemotherapy }\end{array}$ & $\begin{array}{l}\text { Adjusted for poly- } \\
\text { chemotherapy }\end{array}$ & $\begin{array}{l}\text { Adjusted for poly- } \\
\text { chemotherapy }\end{array}$ & $\begin{array}{l}\text { Adjusted for age and } \\
\text { right side }\end{array}$ \\
\hline $\begin{array}{l}\text { MPV (per 1fL } \\
\text { increase) }\end{array}$ & $\begin{array}{c}0.95(0.81-1.12 \\
p=0.556)\end{array}$ & $\begin{array}{c}0.83(0.68-1.02 \\
p=0.074)\end{array}$ & $\begin{array}{l}0.81(0.62-1.05 \\
p=0.113)\end{array}$ & $\begin{array}{c}0.87(0.62-1.22, \\
p=0.426)\end{array}$ & $\begin{array}{c}1.11(0.93-1.33 \\
p=0.248)\end{array}$ \\
\hline $\begin{array}{l}\text { Stage III (vs. Stage } \\
\text { II) }\end{array}$ & $\begin{array}{l}2.14(1.30-3.54 \\
p=0.003)\end{array}$ & N/A & N/A & N/A & N/A \\
\hline Polychemotherapy & N/A & $\begin{array}{c}0.52(0.34-0.80, \\
p=0.003)\end{array}$ & $\begin{array}{c}0.65(0.40-1.06 \\
p=0.085)\end{array}$ & $\begin{array}{c}0.94(0.48-1.87 \\
p=0.867)\end{array}$ & $\begin{array}{c}0.80(0.60-0.97 \\
p=0.021)\end{array}$ \\
\hline $\begin{array}{l}\text { Age (per } 10 \text { years } \\
\text { increase) }\end{array}$ & N/A & N/A & N/A & N/A & $\begin{array}{c}0.75(0.63-0.89, \\
p=0.001)\end{array}$ \\
\hline $\begin{array}{l}\text { Metachronous } \\
\text { metastasis }\end{array}$ & N/A & N/A & N/A & N/A & $\begin{array}{c}1.65(1.10-2.47 \\
p=0.016)\end{array}$ \\
\hline
\end{tabular}

Hazard ratio of 3-year RFS (recurrence free survival), 6-months PFS (progression free survival) and 6-months OS (overall survival) per 1fL increase of MPV

$B S C$ best supportive care, $R F S$ recurrence free survival, $P F S$ progression free survival, $O S$ overall survival, $H R$ hazard ratio, $C I$ confidence interval, $P p$ value, $M P V$ mean platelet volume, $N / A$ not applicable

Yet the prognostic and predictive value of MPV might be varyingly strong in different cancer entities. Despite a relatively large sample size in many settings, the results of our study failed to reach significance in most cases, indicating that MPV is only a weak predictor for disease outcome in CRC. Since to date only positive, significant results regarding the association of MPV and CRC prognosis have been published a possible publication bias must be considered. Therefore, taking the results of the present study into account further research is warranted to clarify the impact of MPV on CRC prognosis.

Some limitations of this study are worth to be mentioned. First, selection bias cannot be excluded entirely due to the retrospective single center study design. Second, we did not exclude patients with conditions that might influence laboratory MPV values as did other studies before, but we think that therefore our results are closer and more relevant to clinical practice. The intention was to analyze a potential biomarker applicable for many CRC patients in different settings rather than for a selected cohort. All patients included in this study who underwent surgery or received chemotherapy were fit enough for treatment, and therefore altered MPV levels due to other severe diseases seem unlikely. Third, the relatively small sample size in later treatment lines must be noticed.

In conclusion, the prognostic and predictive role of MPV in CRC patients remains unclear. Based on our study results, MPV is a weak biomarker in CRC and therefore hardly viable for clinical practice. 
A

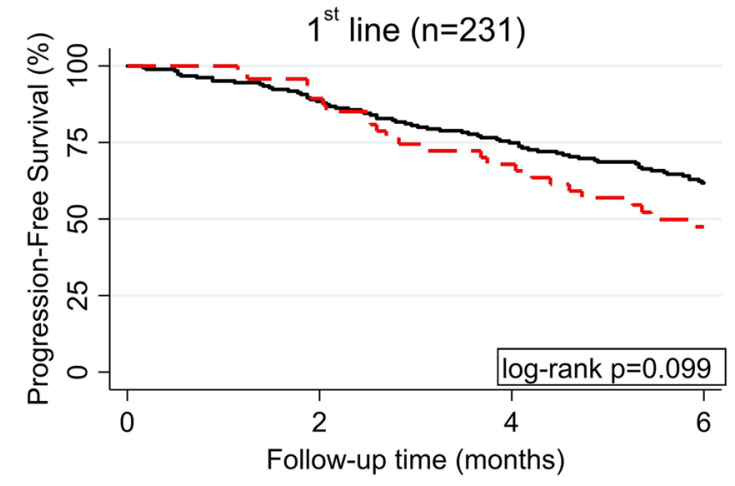

Number at risk (events)

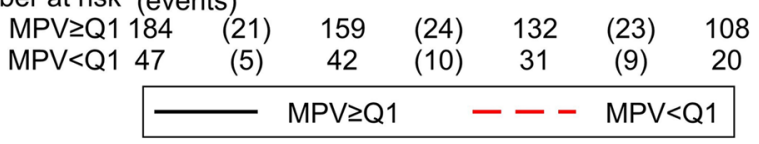
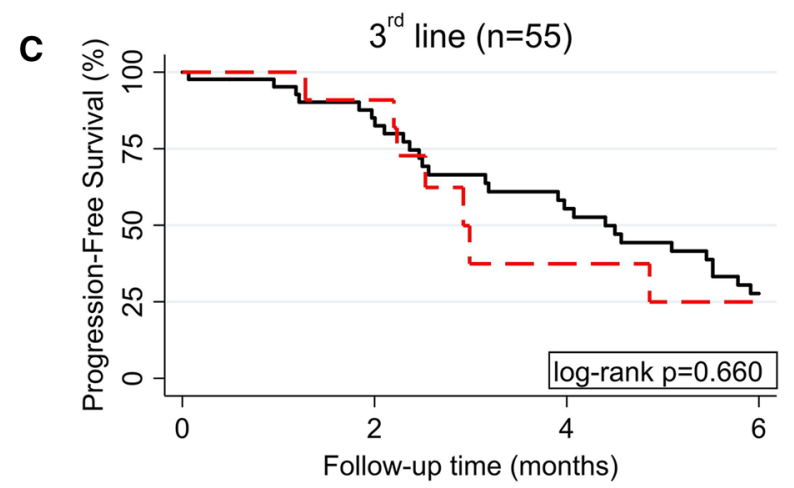

Number at risk (events)

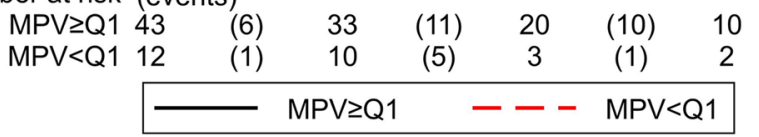

B $\odot \circ \quad 2^{\text {nd }}$ line $(n=117)$

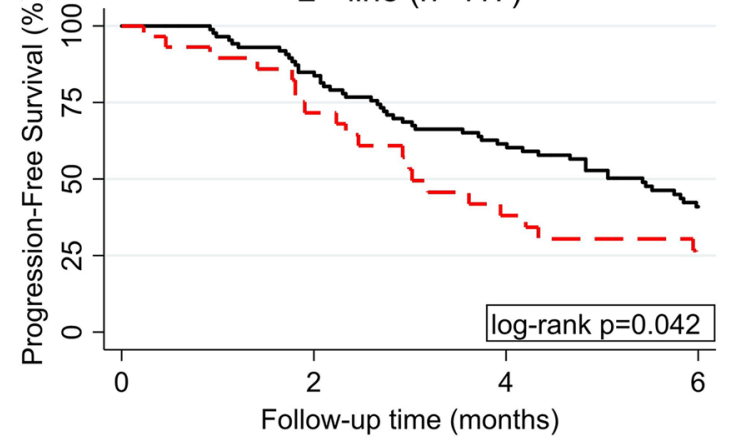

Number at risk (events)

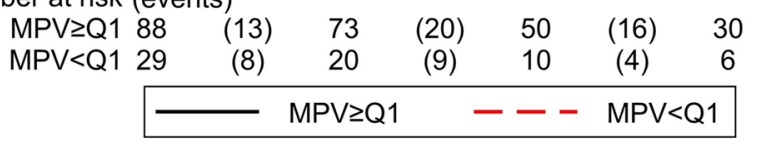

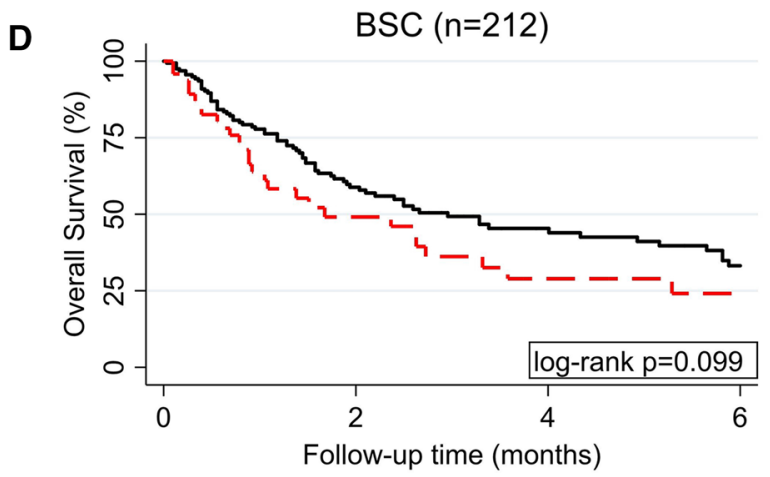

Number at risk (events)

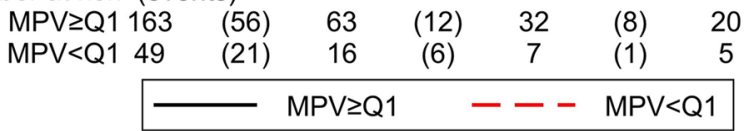

Fig. 2 Kaplan Meier curve according to MPV $\geq$ Q1 vs. MPV $<$ Q1 for progression free survival in the 1st (a), 2nd (b) and 3rd (c) palliative treatment line and overall survival in best supportive care (d)

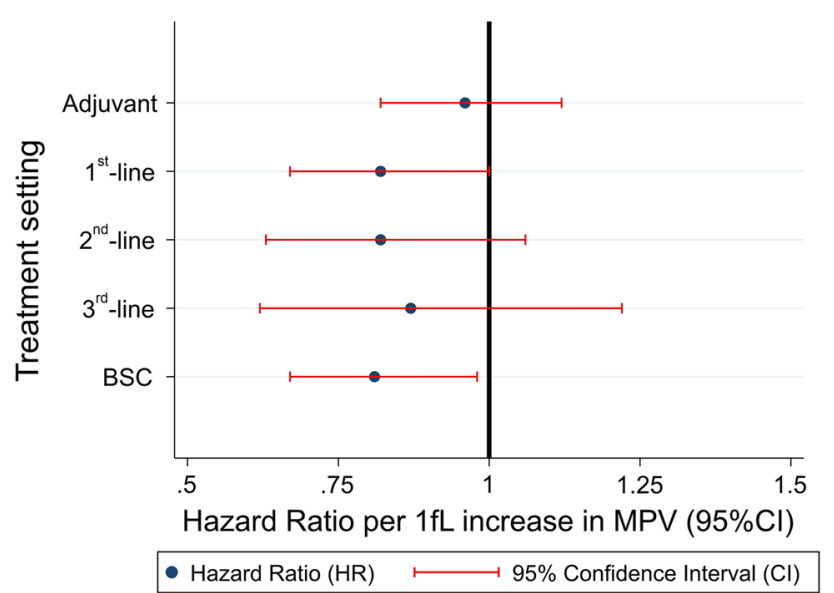

Fig. 3 Forest plot indicating the association between MPV and the respective hazard ratio for 3-year recurrence free survival in the adjuvant setting, 6-months progression free survival in first, second and third palliative treatment line and 6-months overall survival in best supportive care
Acknowledgements Open access funding provided by Medical University of Graz.

Author contributions Conceived and designed the study: DAB FP MS AG. Performed statistical analyses: FP. Interpreted the results: DAB FP HS MS AG. Wrote the first draft of the manuscript: DAB FP. Contributed to the writing of the manuscript: DAB JMR FP MAS AKK TN JS HS MP MS AG Agree with the manuscript's results and conclusions: DAB JMR FP MAS AKK TN JS HS MP MS AG. ICMJE criteria for authorship read and met DAB JMR FP MAS AKK TN JS HS MP MS AG

Funding The authors have no funding to disclose.

\section{Compliance with ethical standards}

Conflict of interest The authors declare that they have no conflict of interest. 
Ethics approval The study was approved by the IRB of the medical university of Graz prior any patient-related activities were performed (No. 25-458 ex 12/13).

Informed consent Written informed consent was not obtained from individual patients, because this is not mandated in Austria for retrospective database studies given approval by an ethics committee.

Availability of data and materials The dataset for this study is not publicly available by request of the local ethic committee in order to protect the anonymity of the patients.

OpenAccess This article is distributed under the terms of the Creative Commons Attribution 4.0 International License (http://creativeco mmons.org/licenses/by/4.0/), which permits unrestricted use, distribution, and reproduction in any medium, provided you give appropriate credit to the original author(s) and the source, provide a link to the Creative Commons license, and indicate if changes were made.

\section{References}

1. Siegel RL, Miller KD, Jemal A. Cancer statistics, 2017. CA Cancer J Clin. 2017;67(1):7-30.

2. O'Connell MJ, Campbell ME, Goldberg RM, Grothey A, Seitz JF, Benedetti JK, et al. Survival following recurrence in stage II and III colon cancer: findings from the ACCENT data set. J Clin Oncol. 2008;26(14):2336-41.

3. van der Geest LG, Lam-Boer J, Koopman M, Verhoef C, Elferink MA, de Wilt JH. Nationwide trends in incidence, treatment and survival of colorectal cancer patients with synchronous metastases. Clin Exp Metast. 2015;32(5):457-65.

4. Pichler M, Stiegelbauer V, Vychytilova-Faltejskova P, Ivan C, Ling H, Winter E, et al. Genome-Wide miRNA Analysis Identifies miR-188-3p as a novel prognostic marker and molecular factor involved in colorectal carcinogenesis. Clin Cancer Res. 2017;23(5):1323-33.

5. Gasparyan AY, Ayvazyan L, Mikhailidis DP, Kitas GD. Mean platelet volume: a link between thrombosis and inflammation? Curr Pharm Des. 2011;17(1):47-58.

6. Riedl J, Kaider A, Reitter EM, Marosi C, Jager U, Schwarzinger $\mathrm{I}$, et al. Association of mean platelet volume with risk of venous thromboembolism and mortality in patients with cancer. Results from the Vienna Cancer and Thrombosis Study (CATS). Thromb Haemost. 2014;111(4):670-8.

7. Haemmerle M, Stone RL, Menter DG, Afshar-Kharghan V, Sood AK. The platelet lifeline to cancer: challenges and opportunities. Cancer Cell. 2018;33(6):965-83.

8. Tesfamariam B. Involvement of platelets in tumor cell metastasis. Pharmacol Ther. 2016;157:112-9.

9. Inagaki N, Kibata K, Tamaki T, Shimizu T, Nomura S. Prognostic impact of the mean platelet volume/platelet count ratio in terms of survival in advanced non-small cell lung cancer. Lung Cancer. 2014;83(1):97-101.

10. Wang X, Cui MM, Xu Y, Liu L, Niu Y, Liu T, et al. Decreased mean platelet volume predicts poor prognosis in invasive bladder cancer. Oncotarget. 2017;8(40):68115-22.

11. Seles M, Posch F, Pichler GP, Gary T, Pummer K, Zigeuner R, et al. Blood platelet volume represents a novel prognostic factor in patients with nonmetastatic renal cell carcinoma and improves the predictive ability of established prognostic scores. J Urol. 2017;198(6):1247-52.
12. Oge T, Yalcin OT, Ozalp SS, Isikci T. Platelet volume as a parameter for platelet activation in patients with endometrial cancer. J Obstet Gynaecol. 2013;33(3):301-4.

13. Kilincalp S, Ekiz F, Basar O, Ayte MR, Coban S, Yilmaz B, et al. Mean platelet volume could be possible biomarker in early diagnosis and monitoring of gastric cancer. Platelets. 2014;25(8):592-4.

14. Karaman K, Bostanci EB, Aksoy E, Kurt M, Celep B, Ulas $\mathrm{M}$, et al. The predictive value of mean platelet volume in differential diagnosis of non-functional pancreatic neuroendocrine tumors from pancreatic adenocarcinomas. Eur J Intern Med. 2011;22(6):e95-8.

15. Pyo JS, Sohn JH, Kang G. Diagnostic and prognostic roles of the mean platelet volume in malignant tumors: a systematic review and meta-analysis. Platelets. 2016;27(8):722-8.

16. Li N, Yu Z, Zhang X, Liu T, Sun YX, Wang RT, et al. Elevated mean platelet volume predicts poor prognosis in colorectal cancer. Sci Rep. 2017;7(1):10261.

17. Tuncel T, Ozgun A, Emirzeoglu L, Celik S, Bilgi O, Karagoz B. Mean platelet volume as a prognostic marker in metastatic colorectal cancer patients treated with bevacizumab-combined chemotherapy. Asian Pac J Cancer Prev. 2014;15(15):6421-3.

18. Wodarczyk M, Kasprzyk J, Sobolewska-Wodarczyk A, Wodarczyk J, Tchorzewski M, Dziki A, et al. Mean platelet volume as a possible biomarker of tumor progression in rectal cancer. Cancer Biomark. 2016;17(4):411-7.

19. Li JY, Li Y, Jiang Z, Wang RT, Wang XS. Elevated mean platelet volume is associated with presence of colon cancer. Asian Pac J Cancer Prev. 2014;15(23):10501-4.

20. Mantovani A, Allavena P, Sica A, Balkwill F. Cancer-related inflammation. Nature. 2008;454(7203):436-44.

21. Riedl JM, Posch F, Moik F, Bezan A, Szkandera J, Smolle MA, et al. Inflammatory biomarkers in metastatic colorectal cancer: prognostic and predictive role beyond the first line setting. Oncotarget. 2017;8(56):96048-61.

22. Kemal Y, Demirag G, Ekiz K, Yucel I. Mean platelet volume could be a useful biomarker for monitoring epithelial ovarian cancer. J Obstet Gynaecol. 2014;34(6):515-8.

23. Cho SY, Yang JJ, You E, Kim BH, Shim J, Lee HJ, et al. Mean platelet volume/platelet count ratio in hepatocellular carcinoma. Platelets. 2013;24(5):375-7.

24. Riedl J, Kaider A, Marosi C, Prager G, Eichelberger B, Koder S, et al. PO-63-exhausted platelets in cancer patients with high risk of venous thromboembolism and poor prognosis. Thromb Res. 2016;140(Suppl 1):S199-200.

25. Yun ZY, Zhang X, Liu ZP, Liu T, Wang RT, Chen H. Association of decreased mean platelet volume with renal cell carcinoma. Int J Clin Oncol. 2017;22(6): 1076-80.

26. Kilincalp S, Coban S, Akinci H, Hamamci M, Karaahmet F, Coskun Y, et al. Neutrophil/lymphocyte ratio, platelet/lymphocyte ratio, and mean platelet volume as potential biomarkers for early detection and monitoring of colorectal adenocarcinoma. Eur J Cancer Prev. 2015;24(4):328-33.

27. Al-Zoughbi W, Huang J, Paramasivan GS, Till H, Pichler M, Guertl-Lackner B, et al. Tumor macroenvironment and metabolism. Semin Oncol. 2014;41(2):281-95.

28. Kumagai S, Tokuno J, Ueda Y, Marumo S, Shoji T, Nishimura $\mathrm{T}$, et al. Prognostic significance of preoperative mean platelet volume in resected non-small-cell lung cancer. Mol Clin Oncol. 2015;3(1):197-201.

Publisher's Note Springer Nature remains neutral with regard to jurisdictional claims in published maps and institutional affiliations. 


\section{Affiliations}

\section{A. Barth ${ }^{1}$ - J. M. Riedl ${ }^{1}$ - F. Posch ${ }^{1}$ - M. A. Smolle ${ }^{1}$ - A.-K. Kasparek ${ }^{1} \cdot$ T. Niedrist $^{2} \cdot$ J. Szkandera ${ }^{1}$ - H. Stöger ${ }^{1}$. M. Pichler ${ }^{1,4} \cdot$ M. Stotz ${ }^{1} \cdot$ A. Gerger ${ }^{1,3}$}

D. A. Barth

dominik.barth@stud.medunigraz.at

J. M. Riedl

j.riedl@stud.medunigraz.at

F. Posch

florian.posch@medunigraz.at

M. A. Smolle

maria.smolle@medunigraz.at

A.-K. Kasparek

anne.kasparek@klinikum-graz.at

T. Niedrist

tobias.niedrist@medunigraz.at

J. Szkandera

joanna.szkandera@medunigraz.at

H. Stöger

herbert.stoeger@medunigraz.at
M. Pichler

martin.pichler@medunigraz.at; mpichler@mdanderson.org

A. Gerger

armin.gerger@gmx.at

1 Division of Clinical Oncology, Department of Medicine, Comprehensive Cancer Center Graz, Medical University of Graz, Auenbruggerplatz 15, $8036 \mathrm{Graz}$, Austria

2 Clinical Institute of Medical and Chemical Laboratory Diagnostics, Medical University of Graz, Auenbruggerplatz 15, 8036 Graz, Austria

3 Center for Biomarker Research in Medicine, Stiftingtalstrasse 5, 8010 Graz, Austria

4 Department of Experimental Therapeutics, The University of Texas MD Anderson Cancer Center, 1901 Eastroad, Houston, TX 77054, USA 